\title{
Effect of the catalyst system on the reactivity of a polyurethane resin system for RTM manufacturing of structural composites
}

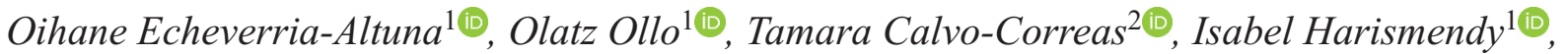 \\ Arantxa Eceiza ${ }^{2 *}(\mathbb{D}$ \\ ${ }^{1}$ Aerospace Unit, Industry and Transport Division, Tecnalia (Member of Basque research \& Technology Alliance), 20009 \\ Donostia-San Sebastian, Spain. \\ ${ }^{2 ‘}$ Materials + Technologies' Research Group (GMT), Department of Chemical and Environmental Engineering, Faculty of \\ Engineering of Gipuzkoa, University of the Basque Country, Plaza Europa 1, 20018 Donostia-San Sebastian, Spain
}

\begin{abstract}
The high versatility of polyurethanes (PU's) is encouraging the development of new formulations for new applications, like their use as a matrix for structural composites. PU's based technology offers some advantages, such as fatigue resistance and fast curing cycles. However, their high reactivity hinders some manufacturing processes like Resin Transfer Moulding (RTM). This work aimed to achieve a PU resin (PUR) formulation with the required latency and reactivity for the RTM. For this purpose, different catalytic systems based on an epoxide and $\mathrm{LiCl}$ were investigated. The reactivity of the systems was evaluated through Differential Scanning Calorimetry (DSC) and rheology tests, and the curing reaction and viscosity were modelled. Furthermore, the RTM process of a representative composite part was simulated. Results demonstrated the processability improvements when the $\mathrm{LiCl}$ was incorporated into the isocyanate component of the formulation combined with a monool or a diol. It was observed that these combinations contribute to the encapsulation of the $\mathrm{LiCl}$ between the as formed urethane groups by hydrogen bonding, providing the desired latency and acting as a delayed action catalyst. Once the reaction started and the encapsulation was deactivated, an alkoxide was formed to act as a catalyst. Encapsulation was more effective with the diol, providing a higher latency.
\end{abstract}

Keywords: thermosetting resins, polyurethane, RTM, catalyst

\section{Introduction}

Polyurethanes (PU's) are a versatile family of polymers, which, depending on the chemical structure of the reactants give rise to a wide variety of polymers with many different properties and applications [1]. That is why new applications and opportunities are appearing for these materials $[2,3]$. PU's represent an interesting alternative to the commonly used epoxy resins in structural composites due to their higher toughness and fatigue resistance $[4,5]$.
In automobiles, materials with a high fatigue tolerance are essential to exploit lightweight potential to its fullest extent. However, in the mass-production of automobiles, speed is paramount, and the newly developed materials should allow high production rates. This is why some developments in the field of PU's for composites are targeting the resin transfer moulding (RTM) process $[4,6]$, which allows the application of short cycle times in the production of structural composites components. For a successful

\footnotetext{
${ }^{*}$ Corresponding author, e-mail: arantxa.eceiza@ehu.eus
} (C) BME-PT 
RTM process, the novel PU thermoset resins (PUR) should have initially low viscosity to achieve a good wetting and fast and controllable reaction to allow fast curing. The high reactivity and short cure times of PURs [2, 6-8] result in an abrupt and premature increase in viscosity that makes them not suitable for RTM. Therefore, it is necessary to develop new catalyst formulations to achieve a certain latency to maintain a low viscosity in the wetting step.

Different types of catalysts are used for PUR, the most common being the low molecular weight tertiary amines, such as 1,4-diazabicyclo[2.2.2]octane (DABCO) and 2-[2-(dimethylamino)ethoxy]- $N, N$ dimethylethanamine (BDMAEE), widely used in rigid and elastic foams. $[9,10]$. However, due to their low molecular weight, they have the tendency to release volatile organic compounds (VOC). Reactive amine catalysts functionalised with isocyanate reactive groups (urea, amino or hydroxyl) can bond to the polymer and reduce VOC release [10-12]. In any case, tertiary amines, reactive or not, accelerate the reaction from the beginning, the curing is very fast, and they do not provide the necessary latency to the PUR for RTM.

Organometallic catalysts have also been extensively used in polyurethane reactions [12-14], being inorganic and organic tin compounds, and more specifically tin alkoxides, the most common $[15,16]$. Despite their efficiency, they are susceptible to moisture, reducing their catalytic activity [12]. Another disadvantage is their toxicity due to the residues formed [17].

Delayed action catalysts formed by tertiary amines blocked with organic acids, which can be thermally activated, have been investigated [18]. However, organic carboxylates have a strong corrosive action, causing a faster deterioration of the machine and storage containers due to the release of carboxylic acid [12]. Therefore, they are not a feasible alternative for the RTM process. In addition to the tertiary amines with delayed action catalyst, there are organometallic compounds with delayed action, but in most cases, they are formed by mercury and heavy metals [19]. Another solution of delayed action catalysts consists of using polymers capable of containing or bonding the catalyst in order to encapsulate or link the catalyst to the polymer $[12,20,21]$. In this context, some authors propose to encapsulate one component of the catalyst system within the reaction components through electrostatic interactions [22, 23].
After the component release, the catalyst is formed in situ, and it acts to accelerate the reaction. Pelzer et al. [24] studied the effect of different halides in the catalytic coupling with an epoxide in the presence of different ratios of 4,4'-diphenylmethane diisocyanate (MDI). They observed that at high MDI contents, the intermediate alkoxide formed by the coupling between epoxide and ammonium halide catalyses the formation of isocyanurate. It was shown that when the halide was chloride, the catalysed reaction that leads to the formation of isocyanurate prevails over other paths. Moreover, the ability of $\mathrm{LiCl}$ was reported to coordinate with urethane groups forming a stable complex via electrostatic interactions [25, 26], as well as to form stable intermolecular hydrogen bonding interactions with hydroxyl groups [27]. In this context, adding a stabilised halide salt within a hydroxyl group containing molecule to the isocyanate component to form an urethane prepolymer can be envisaged as an effective strategy for encapsulating the halide salt of the catalyst system within one of the reaction components.

The aim of this work was to achieve a PUR formulation with the required latency and reactivity for the RTM manufacturing of structural PUR based composites. More specifically, the target application was an automotive component subjected to cycling loadings, such as leaf springs. For this purpose, different catalytic systems based on an epoxide and $\mathrm{LiCl}$, separately incorporated within the reaction components, were investigated. The reactivity of the PUR systems was evaluated through differential scanning calorimetry, and rheology tests and the curing reaction and viscosity were modelled. The chemo-rheological resin models considering the viscosity dependence on temperature and curing degree were employed to effectively predict the resin systems-viscosity evolution with time. Finally, in order to evaluate the different alternatives and find the best process parameters of the injection and curing stages of the RTM process, a representative composite part has been simulated with ESI's PAM-RTM software.

\section{Experimental}

\subsection{Materials}

In this work a high reactivity and low viscosity twocomponent commercial thermoset polyurethane resin, supplied by Dow Chemical (Milano, Italia) was employed. The first PUR component was constituted by a polyether-polyol (Voraforce TR 1551-Polyol, 
$\mathrm{OH}$-number $=527 \mathrm{mg} \mathrm{KOH} \mathrm{g}^{-1}$ and viscosity $=$ $750 \mathrm{mPa} \cdot \mathrm{s})$. Hydroxyl number of Voraforce 1551 was determined according to ASTM D 4274-88. The second component was an isocyanate (Voraforce TR 1500-Isocyanate, $\mathrm{NCO}$ equivalent weight $=136 \mathrm{~g} \cdot \mathrm{eq}^{-1}$ and viscosity $=130 \mathrm{mPa} \cdot \mathrm{s}$ ). $\mathrm{NCO}$ equivalent weight was determined according to the ASTM D2572-97. Three different catalyst systems were evaluated. CAT1 is a two-component system formed by an epoxide (1,4-butanediol diglycidyl ether, BDDE) and a halide salt $(\mathrm{LiCl})$. CAT2 is formed by BDDE and $\mathrm{LiCl}$ dissolved in a low molecular mass biobased cyclic diol (1,4:3,6-dianhydro-D-glucitol or D-isosorbide, DAS). CAT3 is formed by BDDE and LiCl dissolved in a low molecular mass aliphatic monool (diethylene glycol butyl ether, BDG). All the catalysts components were supplied by Sigma Aldrich (St. Louis, USA). Catalysts components were used as received.

\subsection{Synthesis}

Four PUR systems were synthesised, three catalysed and one without additional catalyst as reference. The isocyanate index was maintained constant (equal to 1.2) for all the PUR systems studied. Designation and composition of the PUR systems are summarised in Table 1. All formulations are based on 150 parts by weight of isocyanate [pbw].

Before the polyurethane synthesis reaction, both polyol and isocyanate were degassed separately under vacuum at $1000 \mathrm{mbar}$ and $1000 \mathrm{rpm}$ for $30 \mathrm{~min}$. The non-catalysed system (PUR-REF) consists on the reaction of previously degassed polyol and isocyanate components. The reaction components were prepared as shown in Figure 1a.

The catalysed PUR systems (PU-CAT1, PU-CAT2 and PU-CAT3) consist of the reaction of a polyol and epoxide based mixture (Part A) and an isocyanate based prepolymer (Part B) formed just before the mixing of both components (Figure 1b). For Part A preparation the polyol and epoxide were mixed at room temperature and under nitrogen at $1000 \mathrm{rpm}$ for 15 min, obtaining the Part A mixture. ForPart B, the $\mathrm{LiCl}$ is used alone (CAT1) or dissolved in DAS (CAT2) or in BDG (CAT3) after mixing for $30 \mathrm{~min}$ at $1000 \mathrm{rpm}$ and $80^{\circ} \mathrm{C}$ under nitrogen. After that it was mixed with isocyanate at $1000 \mathrm{rpm}$ and $50^{\circ} \mathrm{C}$ for $4 \mathrm{~h}$ under nitrogen to obtain the isocyanate prepolymer. Finally, Part A mixture and isocyanate prepolymer were mixed with the same procedure as for the uncatalysed system (Figure 1a).

\section{Characterisation}

\subsection{Rheological characterisation}

Rheological tests were carried out on a HAAKE RheoStress 6000 Rheometer (Thermo Fisher Scientific, Massachusetts, USA), running in an oscillating stress mode at a frequency of $1 \mathrm{~Hz}$. Amplitude was held constant in the Linear Viscoelastic Range (LVR) throughout the test. A gap separation of $1 \mathrm{~mm}$ and disposable parallel plates of $60 \mathrm{~mm}$ diameter were used. Experiments were performed at both isothermal or time sweep test, and dynamic or temperature sweep test conditions. Time sweep tests were carried out at different temperatures ranging from 50 to $90^{\circ} \mathrm{C}$ whereas temperature sweep tests were performed from 25 to $200^{\circ} \mathrm{C}$ at a constant heating rate of $5^{\circ} \mathrm{C} \cdot \mathrm{min}^{-1}$. Storage and loss moduli, $G^{\prime}$ and $G^{\prime \prime}$ respectively, and complex viscosity, $\eta^{*}$, were measured over time or temperature in isothermal or dynamic conditions. The gelation time, tgel, was taken as $G^{\prime}$ and $G^{\prime \prime}$ crossover $\left(G^{\prime}=G^{\prime \prime}\right)$.

\subsection{Differential scanning calorimetry}

Differential scanning calorimetry (DSC) tests were carried out on a TA Instruments DSC Q100 (TA Instruments, New Castle, USA) calorimeter in both dynamic and isothermal conditions. The dynamic experiments were performed from 20 to $200^{\circ} \mathrm{C}$ at three heating rates 5,10 and $20^{\circ} \mathrm{C} \cdot \mathrm{min}^{-1}$. Isothermal experiments were performed at temperatures ranging from 50 to $120^{\circ} \mathrm{C}$. All samples were subjected to a

Table 1. Designation and composition of synthesised thermoset polyurethanes.

\begin{tabular}{|l|c|c|c|c|c|c|}
\hline \multirow{3}{*}{ System } & \multicolumn{7}{c|}{$\begin{array}{c}\text { Components ratio } \\
\text { [pbw] }\end{array}$} \\
\cline { 2 - 7 } & Polyol & Isocyanate & LiCl & BDDE & DAS & BDG \\
\hline PUR-REF & 100.00 & 150 & - & - & - & - \\
\hline PUR-CAT1 & 99.92 & 150 & 2.31 & 5.56 & - & - \\
\hline PUR-CAT2 & 83.00 & 150 & 2.31 & 5.56 & 10.19 & - \\
\hline PUR-CAT3 & 92.60 & 150 & 2.31 & 5.56 & - & 10.19 \\
\hline
\end{tabular}




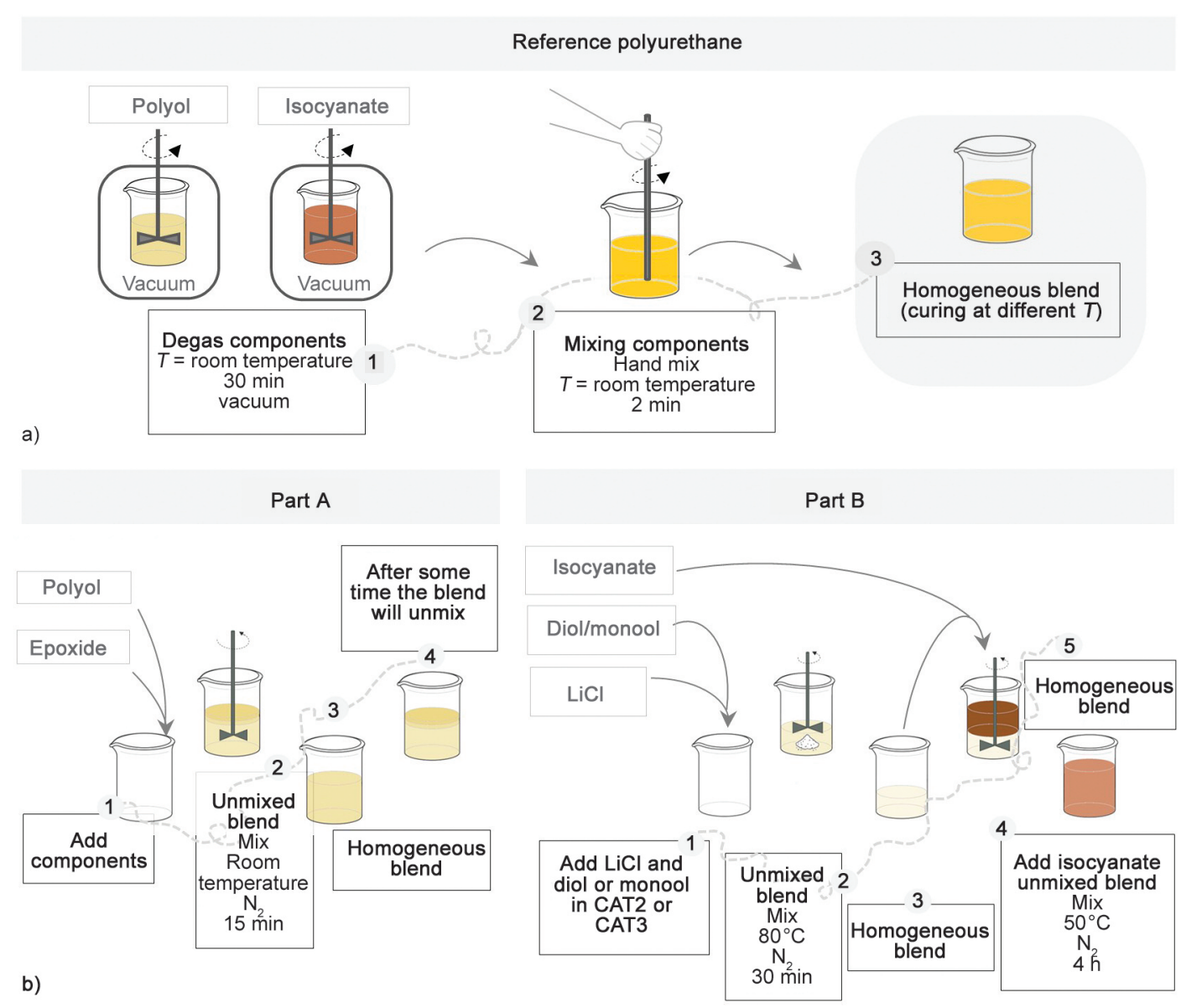

Figure 1. a) Reference polyurethane sample preparation and b) Part A and Part B preparation of the catalysed systems.

subsequent dynamic scan from 20 to $200^{\circ} \mathrm{C}$ at $10{ }^{\circ} \mathrm{C} \cdot \mathrm{min}^{-1}$ to determine the residual heat of reaction and the glass transition temperature, $T_{\mathrm{g}}$, of the cured material. The $T_{\mathrm{g}}$ was taken as the midpoint of the heat capacity change and the total heat of reaction $\left(H_{\mathrm{T}}\right)$ was calculated from the integration of the area of the exothermic peaks.

The curing rates $(\mathrm{d} \alpha / \mathrm{d} t)$ from the heat flow curves obtained in the dynamic and isothermal DSC tests Equation (1) were integrated to calculate the degree of cure $(\alpha)$ profiles Equation (2):

$H=\frac{\mathrm{d} H}{\mathrm{~d} t}=\frac{\mathrm{d} \alpha}{\mathrm{d} t} H_{\mathrm{T}}$

$\alpha=\int_{0}^{\mathrm{t}} \frac{\mathrm{d} \alpha}{\mathrm{d} t} \mathrm{~d} t$

where $H$ is the instantaneous heat evolved during the polymerisation reaction of the resin, and $H_{\mathrm{T}}$ is the total heat after the curing process.

\section{Results and discussion}

Viscosity during the resin curing evolves with time and depends on degree of cure and temperature. In the case of a resin system suitable for high production rate RTM, a combination of low reactivity in the first part of the process and high reactivity in the following steps is necessary. Figure 2a shows schematically the desired viscosity evolution curve for the suitable RTM resin system. Some latency is needed in the first part of the process (resin injection) to maintain a low viscosity value and to facilitate the fibre impregnation. Then, a high reactivity is desired to reduce curing times and allow fast production cycles. Viscosity results from oscillatory temperature sweep tests of the four PUR systems are shown in Figure 2b. As has already been mentioned, the latency in the first part of the curing reaction is necessary to guarantee low viscosity values and obtain an adequate mould filling. Normally, for RTM resin systems, process temperatures are in the range of $90-120^{\circ} \mathrm{C}$ 

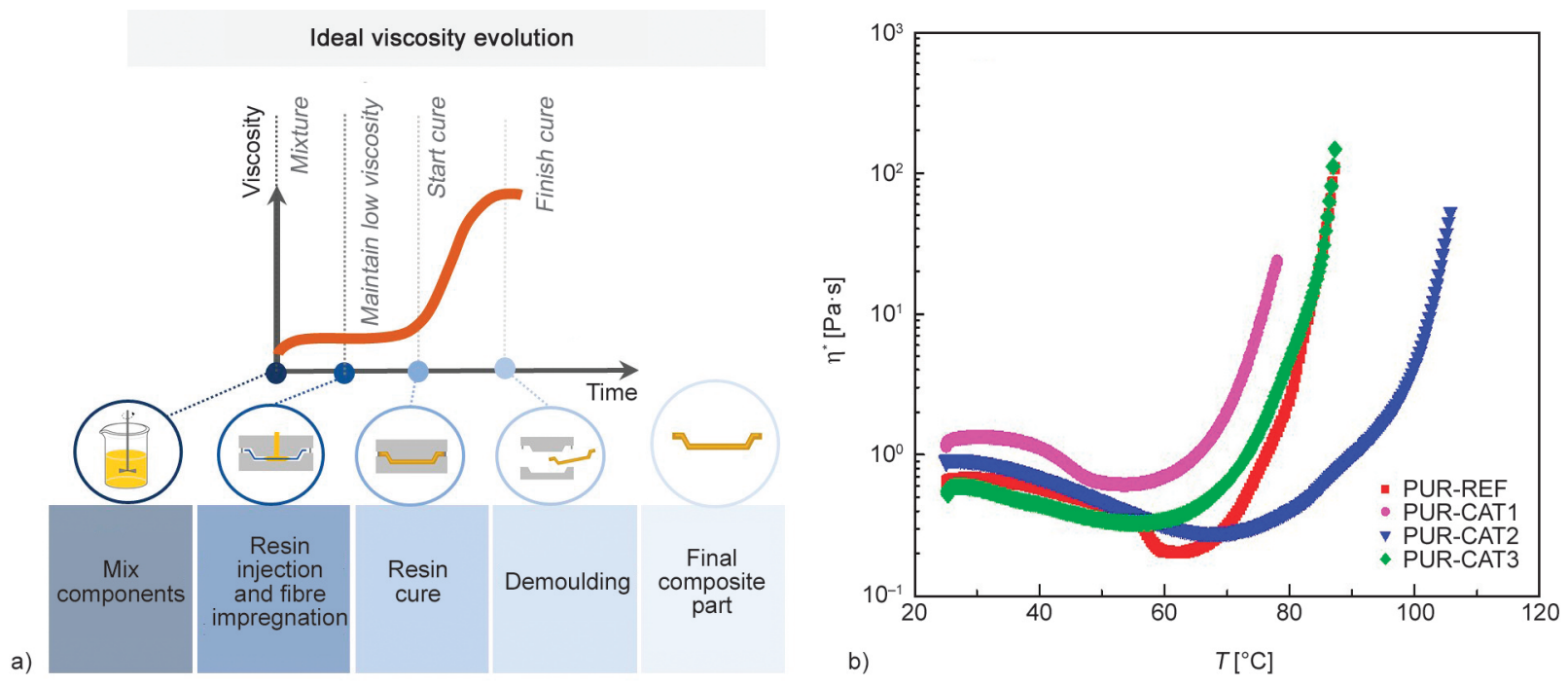

Figure 2. a) Ideal viscosity evolution for the PUR RTM resin systems and b) omplex viscosity evolution with temperature for the different PUR.

to reach the final target properties in process times ranging from 3 to 10 minutes. Therefore, results showed that the PUR-REF system would not be suitable. The viscosity starts increasing at temperatures lower than $70^{\circ} \mathrm{C}$, which means that this system will start to react in a few seconds at the target temperatures and will not have the necessary latency. In the case of the PUR-CAT1 the results have been unsatisfactory since the curing is accelerated, and the viscosity increase starts earlier, and it is faster than the reference system. Moreover, this system shows higher viscosity values from the beginning. For the PURCAT2 system, the viscosity increase starts at a higher temperature showing that the catalyst system provides latency. Furthermore, the shape of the curve at the viscosity increase is similar to the observed for the reference one, which means the cure is fast. PUR-CAT3 system does not show any appreciable improvement compared to the reference systems at this temperature range.

Oscillatory time sweep tests were performed at temperatures between 50 and $90^{\circ} \mathrm{C}$ (Figure 3). Results are in accordance with previous temperature sweep tests. The PUR-REF cure is ultra-fast at temperatures higher than $60^{\circ} \mathrm{C}$ and not suitable for RTM. For PURCAT1, the cure reaction is accelerated at high temperatures worsening the material processability for RTM. PUR-CAT3 only provided a slight improvement compared to the reference. For PUR-CAT2, however, it can be observed that the desired latency is obtained in the first part of the reaction. This delayed action catalytic system seems to be suitable for RTM processing and fulfils the function to provide both latency at the beginning and fast curing at the end of the reaction to the polyurethane resin.

Gel times, tgel, were determined as the $G^{\prime}$ and $G^{\prime \prime}$ moduli crossover in the time sweep tests. The obtained tgel values for each PUR system at the studied temperatures are represented in Figure 4. Results show that PUR-CAT2 provides latency to polyurethane system, increasing the gel times for all the temperatures studied. In this case, although the best results are obtained for PUR-CAT-2, the improvement of latency is also appreciated for PUR-CAT-3.

Again, the lower gel times or the higher reactivities are obtained for PUR-CAT1, showing that this catalyst system is capable of accelerating the reaction, but it cannot provide latency. In PUR-CAT1 the dissociated lithium and chloride encounters the epoxide unimpeded, and they can create an alkoxide, which acts accelerating the reaction of polyurethane [24, 28]. The behaviour observed in PUR-CAT-2 and PURCAT- 3 can be attributed to the developed catalytic system, which is based on the generation of the catalyst in situ, once the reaction between Part A and Part B is initiated. The urethane groups formed once the monool or diol and the isocyanate are mixed to prepare the Part B are able to encapsulate the lithium salt through the formation of a polydentate complex with the salt $[25,27]$. The encapsulation process involves several steps. In the first step of the Part B preparation, the lithium salt is dissociated in the diol or monool due to the electrostatic interactions (Figure 5a).

In the second step of the Part B preparation, the isocyanate reacts with the hydroxyl groups of the diol or monool, creating urethane groups. Thanks to the 

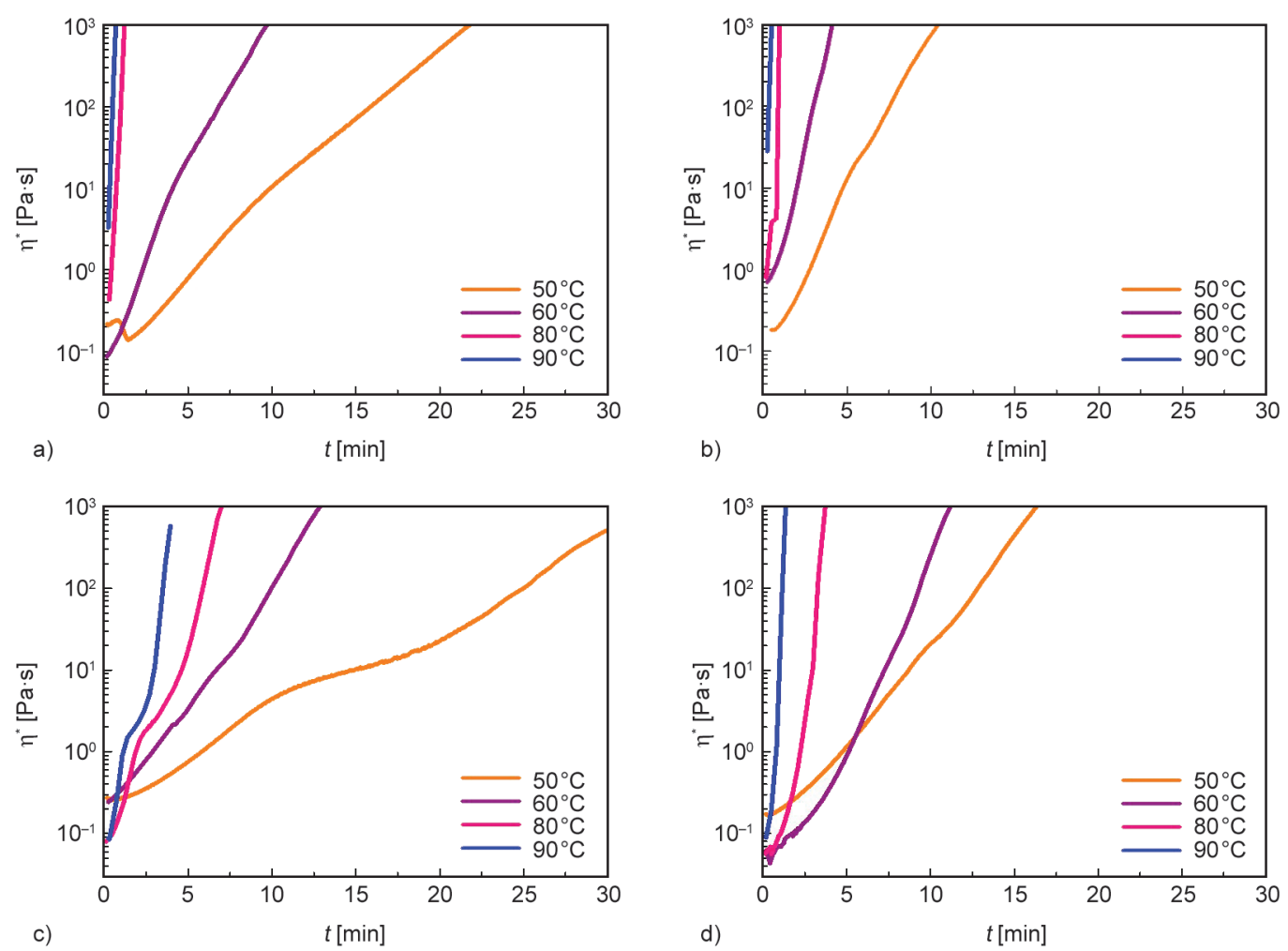

Figure 3. Complex viscosity evolution with time at different temperatures, a) PUR-REF, b) PUR-CAT1, c) PUR-CAT2 and d) PUR-CAT3.

electrostatic interaction, the lithium cation and chloride anion can be associated with the urethane groups $[25,26]$ and create a monodentate or bidentate complex. Figure $5 \mathrm{~b}$ shows the chemical structure evolution in this second step. The salt is caught between the urethane groups encapsulating via electrostatic interactions. In addition, the urethane groups are capable of creating hydrogen bonds among them increasing the encapsulation effectiveness, being stringer in the case of diol. Due to the lack of urethane groups in the PUR-CAT1 Part B, the encapsulation of the $\mathrm{LiCl}$ is not possible. For this reason, the CAT1 accelerates the reaction from the beginning and does



Figure 4. Gel time vs temperature for the studied PUR systems. not provide any latency. Therefore, this system has been discarded as a suitable alternative for the RTM process.

The curing reaction of PUR-REF, PUR-CAT2 and PUR-CAT3 was also characterised by both dynamical and isothermal DSC tests. Figure 6a-6c shows the thermograms obtained in dynamic conditions for the different systems at 5,10 and $20^{\circ} \mathrm{C} \cdot \mathrm{min}^{-1}$. The total heat of reaction, taken as the value obtained at $10^{\circ} \mathrm{C} \cdot \mathrm{min}^{-1}$ was $311 \mathrm{~J} \cdot \mathrm{g}^{-1}$ for the PUR-REF system whereas for the catalysed systems PUR-CAT2 and PUR-CAT3 were 282 and $301 \mathrm{~J} \cdot \mathrm{g}^{-1}$ respectively. The enthalpy difference could be due to the fact that in catalysed systems, the diol and monool were mixed with the isocyanate to form an urethane prepolymer during the Part B preparation. In this step, some isocyanate groups react with hydroxyl groups of the monool or diol in order to produce urethane groups as shown in the Figure 5b. The heat released in this step was not measured in the later DSC cure.

As can be seen in the figures, the reaction is delayed for the catalysed systems. For instance, at $10^{\circ} \mathrm{C} \cdot \mathrm{min}^{-1}$ PUR-REF system peak has a maximum at $80^{\circ} \mathrm{C}$, whereas it appears at 97 and $93^{\circ} \mathrm{C}$ for PUR-CAT2 and PUR-CAT3, respectively. However, it is not evident for the PUR-CAT3 system presented in Figure 6c, 6d 

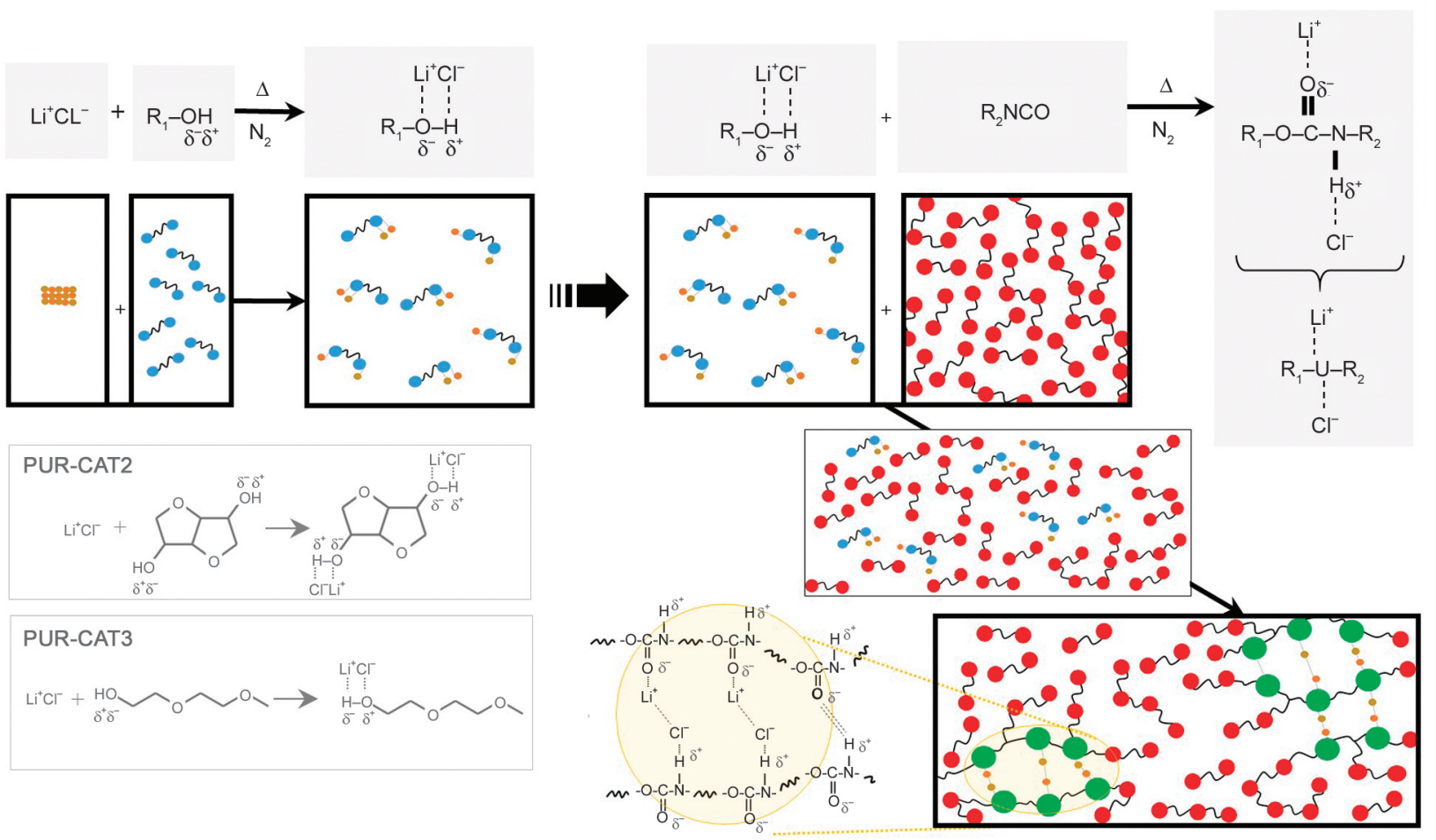

a)

b)

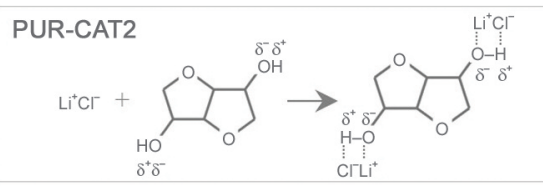

PUR-CAT3

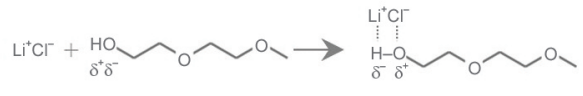



Figure 5. Scheme of the salt encapsulation. a) Salt dissociation in DAS and BDG and b) urethane formation with DAS or BDG and salt encapsulation.


Figure 6. Dynamic DSC thermograms for the different PUR systems at a) $5^{\circ} \mathrm{C} \cdot \mathrm{min}^{-1}$, b) $10^{\circ} \mathrm{C} \cdot \mathrm{min}^{-1}$ and c) $20^{\circ} \mathrm{C} \cdot \mathrm{min}^{-1}$, and d) isothermal DSC thermograms for the different PUR systems at $120^{\circ} \mathrm{C}$. 
at high reaction rates $\left(20^{\circ} \mathrm{C} \cdot \mathrm{min}^{-1}\right.$ and isothermal at $120^{\circ} \mathrm{C}$ ). Furthermore, the shape of the heat flow curve changes and a second peak or an overlapped peak can be appreciated at a higher temperature. This could be attributed to a two-step catalytic mechanism. The first peak in the PUR-CAT2 and in the PUR-CAT3 is associated with polyurethane reaction. At the beginning of the reaction, when the two parts of the system (Part A and Part B) are mixed, due to $\mathrm{LiCl}$ is encapsulated, a delay in the reaction is observed, providing the necessary latency (Figure 7a, First step).

Once the reaction progresses, the heat released is able to break down hydrogen bonds between urethane groups, the encapsulation is destabilised, and the $\mathrm{LiCl}$ encounters the epoxide. $\mathrm{LiCl}$ activates the ring opening of the epoxy group, forming an alkoxide, which acts as a catalyst accelerating the reaction of the polyurethane system, as well as reacting with isocyanate group in excess forming isocyanurate [24, 27]. The second peak in PUR-CAT2 and PUR-CAT3 could be associated with the isocyanurate and additional network formation [29] (Figure 7a, Second step). This second peak appears at $127^{\circ} \mathrm{C}$ in the case of PUR-CAT2 dynamic test at $10^{\circ} \mathrm{C} \cdot \mathrm{min}^{-1}$, whereas for PUR-CAT3 the maximum appears at higher temperatures $150^{\circ} \mathrm{C}$. In the case of PUR-REF systems, although the second peak was overlapped with the main reaction peak, a shoulder was also appreciated. This can involve the achievement of a lower maximum degree of cure at the process temperatures. This effect is also appreciated at the other heating rates studied (Figure 6).
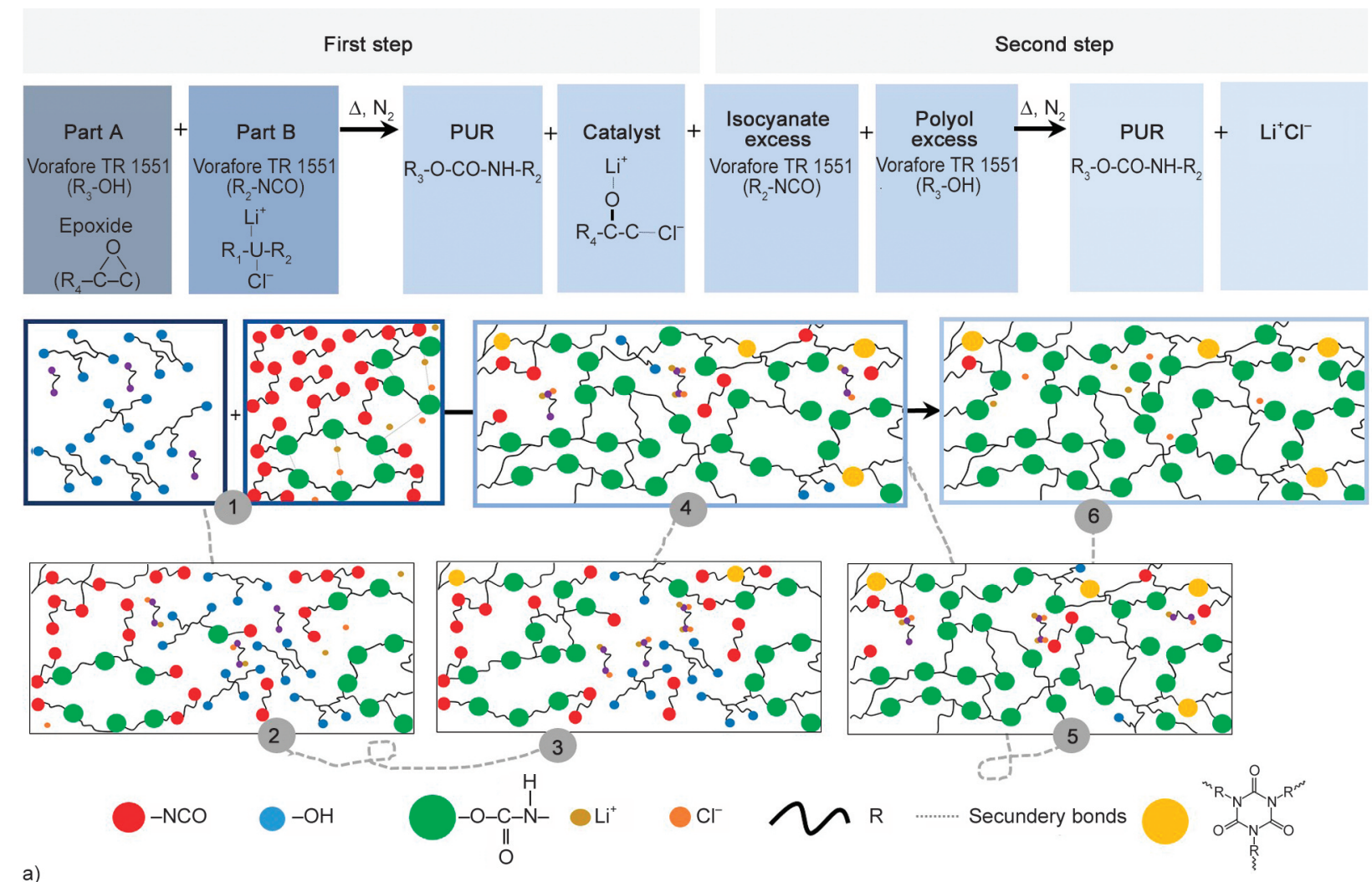

a)

Tree-dimensional network

PUR-REF

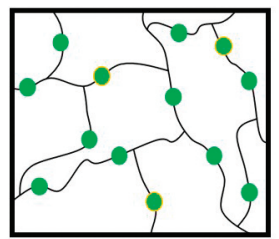

PUR-CAT2

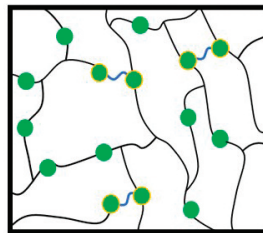

PUR-CAT3

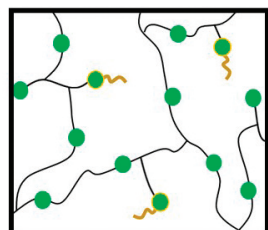

Diol

$\sim$ Monool

b)

Figure 7. a) Scheme of the catalyst mechanism, catalyst production in situ and polyurethane curing and b) polyurethane three-dimensional network for PUR-REF, PUR-CAT2 and PUR-CAT3 systems. 
The $T_{\mathrm{g}}$ calculated from the second DSC scan at $10^{\circ} \mathrm{C} \cdot \mathrm{min}^{-1}$ gives values of $130^{\circ} \mathrm{C}$ for PUR-REF, $133^{\circ} \mathrm{C}$ for PUR-CAT2 and $93{ }^{\circ} \mathrm{C}$ for PUR-CAT3. The changes in $T_{\mathrm{g}}$ are attributed to the effect of the diol and monool on the crosslinking density of the polyurethane. It was expected that crosslinking density decreased with the addition of the diol and monool in the formulation, since both have lower functionality than the Voraforce TR 1551 Polyol (Figure 7b). Nevertheless, in the case of the diol, which has been integrated into PUR-CAT2 system, the $T_{\mathrm{g}}$ value is maintained. This can be attributed to the cycloaliphatic diol structure, which also provides steric hindrance that affects polymer mobility. On the other hand, the monool of PUR-CAT3 is aliphatic and monofunctional and reduces the crosslinking density as shown in Figure 7b, where a schematic representation of the three-dimensional network of the polyurethane systems PUR-REF, PUR-CAT2 and PUR-CAT3 is depicted.

Isothermal experiments were carried out at temperatures ranging between 50 and $120^{\circ} \mathrm{C}$. Figure $6 \mathrm{~d}$ shows as an example the results obtained at $120^{\circ} \mathrm{C}$ (target process temperature). As for the dynamic tests, a shift of the maximum of the heat flow is observed with the addition of the catalyst, suggesting an increase in the latency of the system, being more remarkable for PUR-CAT2 system.

Once the reactivity of the PUR systems was evaluated, the curing reaction and viscosity were modelled. For the cure kinetic modelling, the degree of cure curves obtained from the dynamic and isothermal DSC tests were fitted to the Kamal-Sourour equation (3) [30]. In order to consider the diffusion effect and have a good fitting in all the degree of cure ranges, we completed thewith a diffusion factor $F(\alpha)$. Equations (3), (4) [31]:

$\frac{\mathrm{d} \alpha}{\mathrm{d} t}=\left(k_{1} \mathrm{e}^{-\frac{\mathrm{E}_{1}}{\mathrm{~T}}}+k_{2} \mathrm{e}^{-\frac{\mathrm{E}_{2}}{\mathrm{~T}}} \alpha^{\mathrm{m}}\right)(1-\alpha)^{\mathrm{n}} F(\alpha)$

$F(\alpha)=\frac{1}{1+\mathrm{e}^{\mathrm{E}_{\mathrm{d}}\left(\alpha-\alpha_{c}\right)}}$

where (Equation (5)):

$E_{\mathrm{d}}=E_{\mathrm{d} 1}+E_{\mathrm{d} 2} T$

and (Equation (6)):

$\alpha_{c}=\alpha_{c 1}+\alpha_{c 2} T$

are temperature dependent adjustable parameters.
In this equation $\alpha$ is the degree of cure, $\mathrm{d} \alpha / \mathrm{d} t$ is the reaction rate, $n$ and $m$ the reaction orders and $T$ the temperature. The variables $k_{1}, E_{1}$ and $k_{2}, E_{2}$ are the preexponential factors and activation energies of the $n^{\text {th }}$ and $m^{\text {th }}$ order reactions, respectively and $\mathrm{F}(\alpha)$ corresponds to the diffusion factor. The activation energies for the first part of the reaction, $E_{1}$, are higher for the catalysed than for the reference systems $\left(1.53 \cdot 10^{4}, 1.10 \cdot 10^{4}\right.$ and $8.80 \cdot 10^{3} \mathrm{~K}$ for PUR-CAT2, PUR-CAT3 and PUR-REF, respectively), confirming their higher latency. The activation energy for the second part, $E_{2}$, is clearly higher for PUR-CAT3 $\left(1.26 \cdot 10^{4}, 9.10 \cdot 10^{3}\right.$ and $6.79 \cdot 10^{3} \mathrm{~K}$ for PUR-CAT3, PUR-REF and PUR-CAT2, respectively) showing a delay of the final part of the cure. For PUR-CAT2 however, the activation energy remains low. As it can be seen in Figure 8 there is a good correlation between the experimental results and the proposed models for all the systems studied.

Figure $8 d$ compares the maximum degrees of cure obtained at each temperature for the different resin systems. As it can be seen, at the temperature range studied, the maximum degree of cure for the catalysed systems is lower than for the uncatalysed system. In the case of PUR-REF maximum degrees of cure from 0.93 to 1 (full cure, at $120^{\circ} \mathrm{C}$ ) are obtained and for PUR-CAT2 and PUR-CAT3 the maximum at $120^{\circ} \mathrm{C}$ are 0.94 and 0.85 , respectively. For PURCAT2 the maximum degree of cure of 0.94 is good enough to avoid postcuring whereas for PUR-CAT3 system would require a postcure at higher temperatures. This is in agreement with the results from the dynamic DSC scans (Figure 6a-6c), where a peak appears at temperatures above $120^{\circ} \mathrm{C}$ for PUR-CAT3. Due to the requirement of postcure process, which is an important disadvantage, the PUR-CAT3 systems were discarded as a real alternative for RTM resin. For the viscosity modelling, the results from the time and temperature sweeps tests for PUR-REF and PUR-CAT2 were fitted to the following equation based on Castro-Macosko model (Equation (7)) [32]:

$$
\eta=\eta_{0} \mathrm{e}^{\frac{\mathrm{E}}{\mathrm{T}}}\left(\frac{1}{1-\alpha}\right)^{\mathrm{p}_{1}+\mathrm{p}_{2} \alpha}
$$

where $\eta$ is the resin viscosity at a given degree of cure $(\alpha)$, temperature $(T)$ and activation energy $(E)$, and $\eta_{0}, p_{1}$ and $p_{2}$ are adjustable parameters.

As it can be seen in Figure 9, there is a good fitting for both systems in the pregel stage. Also, again it is 



Figure 8. Degree of cure curves from DSC isothermal and dynamic tests and model fitting (-), a) PUR-REF, b) PUR-CAT2 and c) PUR-CAT3, and d) maximum degree of cure at different temperatures.

demonstrated that the catalytic system is capable of delaying the reaction. The PUR-REF system reaches a viscosity of $1000 \mathrm{~Pa} \cdot \mathrm{s}$ at $80^{\circ} \mathrm{C}$ in one minute, whereas the viscosity of the PUR-CAT2 at this time is lower than $1 \mathrm{~Pa} \cdot \mathrm{s}$. At $90^{\circ} \mathrm{C}$, this difference is more significant, where the PUR-REF reaches a viscosity of $1000 \mathrm{~Pa} \cdot \mathrm{s}$ in half a minute, whereas for PURCAT2 the viscosity is $0.12 \mathrm{~Pa} \cdot \mathrm{s}$.

Finally, in order to evaluate the PUR systems suitability for manufacturing structural parts by RTM, a representative composite part has been simulated with ESI's PAM-RTM software. The composite part

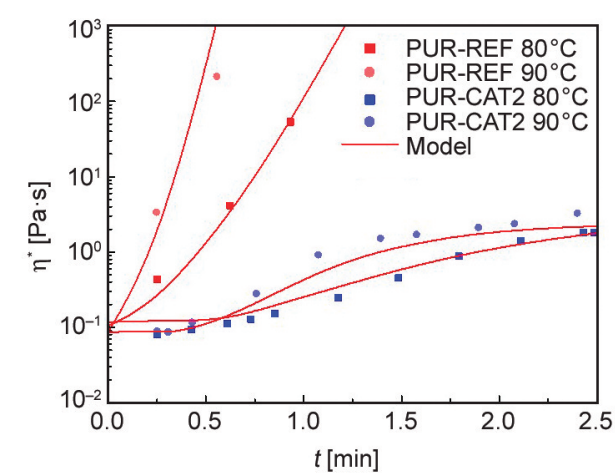

Figure 9. Viscosity evolution with time at 80 and $90^{\circ} \mathrm{C}$ for PUR-REF and PUR-CAT2 systems. Experimental results (symbols) and the rheological model (-). simulated was a leaf spring reinforced with $47 \%$ fibre volume content of high fatigue resistance (ultra-fatigue) unidirectional glass fibre (Ultra Fatigue UD, UV-E-PB-1176 g/m²-1200 mm, Saertex, Saerbeck, Germany). These parts are normally produced with a linear, lateral injection strategy with the resin inlet at the middle point of the part and the outlets at the ends (Figure 10a) so for the evaluations, only half length of the real part was considered. The mesh dimensions used in the simulations are shown in Figure 10b.

The flow of the polyurethane resin through the glass fibre fabric can be described by Darcy's law (Equation (8)):

$Q=\frac{S K}{\varphi \eta} \nabla P$

where $Q$ denotes the resin flow rate, $K$ is the preform permeability, $S$ is the cross-sectional area, $\varphi$ is the porosity, $\eta$ is the resin viscosity, and $P$ represents the pressure. On the other hand, as mentioned previously, resin viscosity depends on resin temperature and time (degree of cure) as described in Equation (7). The temperature used for the simulations was $120^{\circ} \mathrm{C}$ in all the cases, which is a standard temperature for the production of composite automotive parts. Also, two different injection strategies were considered, at 



Figure 10. a) Injection strategy and b) mesh used in the simulation of a reinforced leaf spring.

constant pressure and a constant flow. In the case of constant pressure injections, the simulations have been carried out at different pressures ranging from 70 to 100 bar. PUR-REF is not able to fill the mould in any case, as shown in Figure 11a. This happens because the viscosity starts to increase in a few seconds, and the resin gels, making it impossible to continue mould filling. PUR-REF lack of latency makes this resin system not suitable for the manufacture of leaf springs by RTM. However, PUR-CAT2 system simulations results are satisfactory (Figure 11b). Simulations show the processability of PUR-CAT2 at moderate pressures. At pressures higher than 70 bar, this system can fill the mould in a few seconds. After the mould filling the curing is fast, and in four minutes, the curing is completed without post-curing processes. The PUR-CAT2 provides enough latency to be suitable for RTM.

The simulations at a constant flow rate of $1 \mathrm{~kg} \cdot \mathrm{min}^{-1}$ and 100 bar maximum pressure strengthen the previous results (Figure 11c). The PUR-REF is not capable of filling the mould, and it reaches the maximum pressure and gels before in a few seconds. In the simulation with PUR-CAT2 system, the maximum pressure is reached in 5 seconds, and there is a decrease in filling rate, but the mould is fully filled in only 14 seconds.

\section{Conclusions}

In this work, different catalytic systems based on an epoxide and $\mathrm{LiCl}$ were investigated to achieve the required reactivity for the RTM manufacturing of structural PUR based composites. DSC, rheology and RTM simulation results showed that the PUR-REF commercial system is not suitable for the target application due to the abrupt increase of viscosity during the mould filling step. It is necessary to provide latency to the resin system. When the $\mathrm{LiCl}$ was used alone, as in PUR-CAT1, the salt and the epoxide could form an alkoxide, which acted as a catalyst accelerating the reaction, but the curing rate was increased from the beginning of the reaction, worsening the PUR processability. Adding the diol or monool in the isocyanate component of the formulations, as for PURCAT2 (DAS diol) and PUR-CAT3 (BDG monool), delayed the curing in the first part of the reaction and provided latency in both systems. This is a result of the capability of urethane groups, formed by isocyanate component and diol or triol, to encapsulate the lithium halide via electrostatic interactions. When the reaction progressed, the heat released could break down hydrogen bonds, and the encapsulation was destabilised. After that, the $\mathrm{LiCl}$ encountered the epoxide to form alkoxide, and it acted as a catalyst. The delayed action catalyst with DAS (PUR-CAT2) showed more effective encapsulation, providing more latency. Moreover, for PUR-CAT2 the maximum curing degree obtained was good enough to avoid postcuring, with a $T_{\mathrm{g}}$ of $133^{\circ} \mathrm{C}$, whereas the PURCAT3 system would require a postcure at a higher temperature to achieve the required properties. The RTM simulations demonstrated the PUR-CAT2 processability improvements and the capability to manufacture real automotive structural parts.

\section{Acknowledgements}

We gratefully acknowledge the Basque Government for the financial support through the ELKARTEK 2020 (Project AVANSITE New generation of sustainable composites for advanced manufacturing KK2020/00019) program. The authors also acknowledge the University of the Basque Country (UPV/EHU) in the frame of GIU18/216 Research Group and the Macrobehavior-Mesostructure-Nanotechnology SGIker unit. 
PUR-REF (Constant pressuret)

\begin{tabular}{|c|c|c|c|c|c|c|c|}
\hline \multicolumn{4}{|c|}{70 bar } & \multicolumn{4}{|c|}{$100 \mathrm{bar}$} \\
\hline $\begin{array}{l}\text { Filling time } \\
\text { [s] }\end{array}$ & $\begin{array}{l}\text { Pressure } \\
\text { [bar] }\end{array}$ & $\begin{array}{c}\text { Degree of cure } \\
{[\alpha]}\end{array}$ & $\begin{array}{l}\text { Viscosity } \\
{[\mathrm{Pa} \cdot \mathrm{s}]}\end{array}$ & $\begin{array}{l}\text { Filling time } \\
\text { [s] }\end{array}$ & $\begin{array}{l}\text { Pressure } \\
\text { [bar] }\end{array}$ & $\begin{array}{l}\text { Degree of cure } \\
{[\alpha]}\end{array}$ & $\begin{array}{c}\text { Viscosity } \\
{[\mathrm{Pa} \cdot \mathrm{s}]}\end{array}$ \\
\hline $\begin{array}{r}1.0000 \cdot 10^{6} \\
-9.3333 \cdot 10^{5} \\
-8.6667 \cdot 10^{5} \\
8.0000 \cdot 10^{5} \\
-7.3333 \cdot 10^{5} \\
-6.6667 \cdot 10^{5} \\
-6.0000 \cdot 10^{5} \\
-5.3333 \cdot 10^{5} \\
-4.6667 \cdot 10^{5} \\
-4.0000 \cdot 10^{5} \\
-3.3333 \cdot 10^{5} \\
-2.6667 \cdot 10^{5} \\
-2.0000 \cdot 10^{5} \\
-1.3333 \cdot 10^{5} \\
6.6667 \cdot 10^{4} \\
0.0000 \cdot 10^{0}\end{array}$ & $\begin{array}{r}-70.00 \\
-65.33 \\
-60.67 \\
-56.00 \\
-51.33 \\
-46.67 \\
-42.00 \\
-37.33 \\
-32.67 \\
-28.00 \\
-23.33 \\
-18.67 \\
-14.00 \\
9.33 \\
4.67 \\
0.00 \\
\end{array}$ & $\begin{array}{l}1.0000 \cdot 10^{\circ} \\
-9.3333 \cdot 10^{-1} \\
-8.6667 \cdot 10^{-1} \\
-8.0000 \cdot 10^{-1} \\
-7.3333 \cdot 10^{-1} \\
-6.6667 \cdot 10^{-1} \\
-6.0000 \cdot 10^{-1} \\
-5.3333 \cdot 10^{-1} \\
-4.6667 \cdot 10^{-1} \\
-4.0000 \cdot 10^{-1} \\
-3.3333 \cdot 10^{-1} \\
-2.6667 \cdot 10^{-1} \\
-2.0000 \cdot 10^{-1} \\
1.3333 \cdot 10^{-1} \\
-6.6667 \cdot 10^{-2} \\
0.0000 \cdot 10^{\circ}\end{array}$ & $\begin{array}{l}- \text { inf } \\
\text {-inf } \\
\text {-inf } \\
- \text { inf } \\
- \text { inf } \\
- \text { inf } \\
- \text { inf } \\
- \text { inf } \\
- \text { inf } \\
- \text { inf } \\
- \text { inf } \\
- \text { inf } \\
- \text { inf } \\
- \text { inf } \\
\text { inf } \\
- \text { nan(ind) }\end{array}$ & $\begin{array}{l}1.0000 \cdot 10^{?} \\
-9.3333 \cdot 10^{2} \\
-8.6667 \cdot 10^{2} \\
8.0000 \cdot 10^{?} \\
-7.3333 \cdot 10^{2} \\
-6.6667 \cdot 10^{2} \\
-6.0000 \cdot 0^{2} \\
-5.3333 \cdot 10^{?} \\
-4.6667 \cdot 10^{?} \\
-4.0000 \cdot 10^{2} \\
-3.3333 \cdot 10^{2} \\
-2.6667 \cdot 10^{?} \\
2.0000 \cdot 10^{?} \\
-1.3333 \cdot 10^{2} \\
6.6667 \cdot 10^{?} \\
0.0000 \cdot 10^{2}\end{array}$ & $\begin{array}{r}100.00 \\
93.33 \\
86.67 \\
80.00 \\
73.33 \\
66.67 \\
60.00 \\
53.33 \\
46.67 \\
40.00 \\
33.33 \\
26.67 \\
20.00 \\
13.33 \\
6.67 \\
0.00\end{array}$ & $\begin{array}{l}1.0000 \cdot 10^{0} \\
-9.3333 \cdot 10^{-1} \\
-8.6667 \cdot 10^{-1} \\
-8.0000 \cdot 10^{-1} \\
-7.3333 \cdot 10^{-1} \\
-6.6667 \cdot 10^{-1} \\
6.0000 \cdot 10^{-1} \\
-5.3333 \cdot 10^{-1} \\
4.6667 \cdot 10^{-1} \\
-4.0000 \cdot 10^{-1} \\
3.3333 \cdot 10^{-1} \\
-2.6667 \cdot 10^{-1} \\
2.0000 \cdot 10^{-1} \\
-1.3333 \cdot 10^{-1} \\
6.6667 \cdot 10^{-2} \\
0.0000 \cdot 10^{\circ}\end{array}$ & $\begin{array}{l}- \text { inf } \\
- \text { inf } \\
- \text { inf } \\
- \text { inf } \\
- \text { inf } \\
- \text { inf } \\
- \text { inf } \\
- \text { inf } \\
- \text { inf } \\
- \text { inf } \\
- \text { inf } \\
- \text { inf } \\
- \text { inf } \\
- \text { inf } \\
- \text { inf } \\
- \text {-nan(ind) }\end{array}$ \\
\hline
\end{tabular}

a)

\begin{tabular}{|c|c|c|c|c|c|c|c|}
\hline \multicolumn{8}{|c|}{ PUR-CAT2 (Constant pressure) } \\
\hline \multicolumn{4}{|c|}{70 bar } & \multicolumn{4}{|c|}{100 bar } \\
\hline $\begin{array}{l}\text { Filling time } \\
\text { [s] }\end{array}$ & $\begin{array}{c}\text { Pressure } \\
\text { [bar] }\end{array}$ & $\begin{array}{l}\text { Degree of cure } \\
\qquad[\alpha]\end{array}$ & $\begin{array}{c}\text { Viscosity } \\
{[\mathrm{Pa} \cdot \mathrm{s}]}\end{array}$ & $\begin{array}{l}\text { Filling time } \\
\text { [s] }\end{array}$ & $\begin{array}{l}\text { Pressure } \\
\text { [bar] }\end{array}$ & $\begin{array}{l}\text { Degree of cure } \\
{[\alpha]}\end{array}$ & $\begin{array}{c}\text { Viscosity } \\
{[\mathrm{Pa} \cdot \mathrm{s}]}\end{array}$ \\
\hline 36.85 & 70.00 & -0.571 & 1.660 & 9.039 & -100.00 & 0.2054 & 0.2099 \\
\hline-34.40 & 65.33 & -0.533 & 1.552 & -8.436 & 93.33 & -0.1917 & 0.1984 \\
\hline-31.94 & 60.67 & 0.494 & -1.444 & -7.834 & 86.67 & -0.1780 & 0.1870 \\
\hline-29.48 & 56.00 & -0.456 & 1.337 & -7.231 & 80.00 & 0.1643 & 0.1755 \\
\hline-27.03 & 51.33 & -0.418 & -1.229 & -6.629 & 73.33 & -0.1506 & 0.1640 \\
\hline-24.57 & -46.67 & -0.380 & -1.121 & -6.026 & 66.67 & -0.1369 & -0.1525 \\
\hline-22.11 & 42.00 & -0.342 & -1.014 & -5.423 & 60.00 & -0.1232 & -0.1410 \\
\hline-19.66 & -37.33 & -0.304 & 0.906 & -4.821 & 53.33 & -0.1096 & 0.1296 \\
\hline 17.20 & -32.67 & -0.266 & 0.798 & -4.218 & 46.67 & -0.0959 & 0.1181 \\
\hline 14.74 & 28.00 & 0.228 & 0.691 & -3.618 & 40.00 & 0.0822 & 0.1066 \\
\hline 12.28 & 23.33 & -0.190 & 0.583 & 3.013 & 33.33 & 0.0685 & 0.0951 \\
\hline 9.83 & 18.67 & 0.152 & 0.175 & 2.410 & 26.67 & 0.0548 & 0.0836 \\
\hline 7.37 & 14.00 & -0.114 & 0.368 & 1.808 & 20.00 & 0.0411 & 0.0722 \\
\hline 4.91 & 9.33 & -0.076 & 0.260 & 1.205 & 13.33 & 0.0274 & 0.0607 \\
\hline 2.46 & 4.67 & -0.038 & 0.152 & 0.603 & 6.67 & 0.0137 & 0.0492 \\
\hline 0.00 & 0.00 & 0.000 & 0.45 & 0.000 & 0.00 & 0.0001 & 0.0377 \\
\hline
\end{tabular}

b)

Flow rate $1 \mathrm{~kg} \cdot \mathrm{min}^{-1}$ (Constant flow rate)

\begin{tabular}{|c|c|c|c|c|c|c|c|}
\hline \multicolumn{4}{|c|}{ PUR-REF } & \multicolumn{4}{|c|}{ PUR-CAT2 } \\
\hline $\begin{array}{l}\text { Filling time } \\
\text { [s] }\end{array}$ & $\begin{array}{l}\text { Pressure } \\
\text { [bar] }\end{array}$ & $\begin{array}{l}\text { Degree of cure } \\
{[\alpha]}\end{array}$ & $\begin{array}{l}\text { Viscosity } \\
{[\mathrm{Pa} \cdot \mathrm{s}]}\end{array}$ & $\begin{array}{l}\text { Filling time } \\
\text { [s] }\end{array}$ & $\begin{array}{l}\text { Pressure } \\
\text { [bar] }\end{array}$ & $\begin{array}{l}\text { Degree of cure } \\
{[\alpha]}\end{array}$ & $\begin{array}{c}\text { Viscosity } \\
{[\mathrm{Pa} \cdot \mathrm{s}]}\end{array}$ \\
\hline 7.533 & 100.00 & & & & & & \\
\hline 7.031 & 93.33 & -0.933 & inf & $\pi^{14.82}$ & 100.00 & $\begin{array}{l}0.31 \\
0.29\end{array}$ & 0.4296 \\
\hline 6.529 & 86.67 & 0.867 & inf & 13.83 & 93.33 & $\begin{array}{l}0.29 \\
-0.27\end{array}$ & 0.4009 \\
\hline-6.026 & 80.00 & 0.800 & $\begin{array}{l}\text { - inf } \\
\text { inf }\end{array}$ & 12.85 & 86.67 & -0.25 & 0.3723 \\
\hline-5.524 & 73.33 & 0.733 & inf & 11.89 & 80.00 & -0.23 & 0.3436 \\
\hline-5.022 & 66.67 & -0.667 & $-\inf$ & $\begin{array}{r}-10.87 \\
-988\end{array}$ & 73.33 & -0.21 & 0.3150 \\
\hline-4.520 & 60.00 & -0.600 & -inf & $\begin{array}{l}9.88 \\
889\end{array}$ & 66.67 & -0.18 & 0.2864 \\
\hline-4.018 & 53.33 & -0.533 & inf & $\begin{array}{l}8.89 \\
7.91\end{array}$ & 60.00 & -0.16 & 0.2577 \\
\hline-3.515 & 46.67 & -0.467 & inf & $\begin{array}{l}7.91 \\
6.92\end{array}$ & 53.33 & -0.14 & 0.2291 \\
\hline 3.013 & 40.00 & 0.400 & inf & 5.93 & 46.67 & -0.12 & $\begin{array}{l}0.2005 \\
0.1718\end{array}$ \\
\hline 2.511 & 33.33 & 0.333 & inf & 4.94 & $\begin{array}{l}40.00 \\
3333\end{array}$ & -0.10 & 0.1432 \\
\hline 2.009 & 26.67 & -0.267 & $\inf$ & 3.95 & 26.67 & 0.08 & 0.1145 \\
\hline 1.507 & 20.00 & -0.200 & -inf & 2.96 & 20.00 & -0.06 & 0.0859 \\
\hline-1.004 & 13.33 & 0.133 & inf & 1.98 & 13.33 & -0.04 & 0.0573 \\
\hline 0.502 & 6.67 & 0.067 & inf & 0.99 & 6.67 & -0.02 & 0.0286 \\
\hline 0.00 & 0.00 & 0.000 & -nan(ind) & 0.00 & 0.00 & & 0.0000 \\
\hline
\end{tabular}

c)

Figure 11. Leaf spring simulation at $120^{\circ} \mathrm{C}$ with constant pressure for a) PUR-REF and b) PUR-CAT2, and c) with constant flow rate for PUR-REF and PUR-CAT2. 


\section{References}

[1] Szycher M.: Szycher's handbook of polyurethanes. CRC Press, Boca Raton (1999).

[2] Kreiling S., Fetscher F.: Progress with polyurethane matrix resin technology: High-speed resin transfer molding processes and application examples. in ' $13^{\text {th }}$ annual SPE Automotive Composites Conference. Novi, USA' Vol.1, 288-295 (2013).

https://www.researchgate.net/publication/290986370

[3] Albrecht P., Becher J., Wiemand M., Hindahl J.: Optimizing leaf springs via enhanced composite solutions. JEC Composites Magazine, 24-26 (2019).

[4] Volvo XC90 features polyurethane composite leaf spring. Reinforced Plastics, 58, 7 (2014). https://doi.org/10.1016/S0034-3617(14)70228-0

[5] Rosenberg P., Thoma B., Henning F.: Characterization of epoxy and polyurethane resin systems for manufacturing of high-performance composites in high-pressure rtm process. in ' $15^{\text {th }}$-annual SPE Automotive Composites Conference. Novi, USA’, 1-19 (2015).

https://www.researchgate.net/publication/282286658

[6] Behnisch F., Rosenberg P., Weidenmann A. K., Henning F.: Investigation of the matrix influence on the laminate properties of epoxy- and polyurethane-based CFRPs manufactured with HP-RTM-process. in 'AIP Conference. Lyon, France’ Vol. 1914, 180003 (2017). https://doi.org/10.1063/1.5016789

[7] Bareis D., Heberer D., Connolly M.: Advances in urethane composites: Resins with tunable reaction times. in 'COMPOSITES 2011. Fort Lauderdale, USA' 137791725 (2011).

[8] Angst P., Emig J., Albrecht P.: Sandwich opens huge potential for lightweight engineering. JEC Composites Magazine, 21-24 (2019).

[9] Li R., Liu L., Liu Y., Wang B., Yang J. J., Zhang J.: Research progress of amine catalysts for polyurethane. New Materials and Intelligent Manufacturing, 1, 54-57 (2018). https://doi.org/10.26480/icnmim.01.2018.54.57

[10] Rothe J., Cordelair H., Wehman C.: New catalysts for low VOC in flexible slabstock foam. Journal of Cellular Plastics, 37, 207-220 (2001). https://doi.org/10.1106/X6BV-73PB-6FQC-KCRN

[11] Huhtasaari M. S., Plaumann R., Grimminger J., Kniss J. G., Womack F. D.: Catalysts and silicone surfactants for reduced VOC emissions of polyester slabstock foam. in 'Polyurethanes Expo 2001. Columbus, USA' 431-441 (2001).

https://doi.org/10.1201/9780429332609-60

[12] Silva A. L., Bordado J. C.: Recent developments in polyurethane catalysis: Catalytic mechanisms review. Catalysis Reviews, 46, 31-51 (2004). https://doi.org/10.1081/CR-120027049

[13] Schellekens Y.,van Trimpont B., Goelen P-J., Binnemans K., Smet M., Persoons M-A., de Vos D.: Tin-free catalysts for the production of aliphatic thermoplastic polyurethanes. Green Chemistry, 16, 441-447 (2014). https://doi.org/10.1039/C4GC00873A
[14] Akindoyo J. O., Beg M. D. H., Ghazali S., Islam M. R., Jeyaratnam N., Yuvaraj A. R.: Polyurethane types, synthesis and applications - A review. RSC Advances, 6, 114453-114482 (2016).

https://doi.org/10.1039/C6RA14525F

[15] Devendra R., Edmonds N. R., Söhnel T.: Computational and experimental investigations of the urethane formation mechanism in the presence of organotin(IV) carboxylate catalysts. Journal of Molecular Catalysis A: Chemical, 366, 126-139 (2013). https://doi.org/10.1016/j.molcata.2012.09.015

[16] Devendra R., Edmonds N. R., Söhnel T.: Organotin carboxylate catalyst in urethane formation in a polar solvent: An experimental and computational study. RSC Advances, 5, 48935-48945 (2015).

https://doi.org/10.1039/C5RA03367E

[17] Fent K.: Organotin compounds in municipal wastewater and sewage sludge: Contamination, fate in treatment process and ecotoxicological consequences. Science of the Total Environment, 185, 151-160 (1996). https://doi.org/10.1016/0048-9697(95)05048-5

[18] Jones F. N., Nichols M. E., Pappas S. P.: Organic coatings: Science and technology. Wiley, Hoboken (2017). https://doi.org/10.1002/9781119337201

[19] Christman D. L., Grosse I., Merk1 B. A.: Trimerization catalysts and organo-mercury compounds as co-catalysts for the preparation of noncellular polyurethane elastomers. U.S. Patent 4438248A, USA (1984).

[20] Gao Y., Dong H., Liu L., Yu Y., Tang Z., Bai C., Schmidt T., Feng Y., Chen H.: Tin-containing crystalline copolymers as latent catalysts for polyurethanes. ACS Applied Polymer Materials, 2, 4531-4540 (2020).

https://doi.org/10.1021/acsapm.0c00627

[21] Bitler S. P., Kamp D. A., Wanthal M. A., Sendijarevic A., Altarribasanpons M., Wang J., Frish K. C.: Novel delayed action catalysts for polyurethane applications. in 'Polyurethane World Congress. Amsterdam, Netherlands' 338-345 (1997).

[22] Verbeke H., Verbeke H. G. G., Giannini G., Esbelin C.: In-situ formation of polyurethane catalyst. World Patent WO/2016/202568 (2016).

[23] Liese J., Schütte M., Eling B.: Polyurethane system with long pot life and rapid hardening. World Patent WO/2015/078740 (2015).

[24] Pelzer T., Eling B., Thomas H-J., Luinstra G. A.: Toward polymers with oxazolidin-2-one building blocks through tetra- $n$-butyl-ammonium halides $(\mathrm{Cl}, \mathrm{Br}, \mathrm{I})$ catalyzed coupling of epoxides with isocyanates. European Polymer Journal, 107, 1-8 (2018).

https://doi.org/10.1016/j.eurpolymj.2018.07.039

[25] Yalcinkaya F., Yalcinkaya B., Jirsak O.: Influence of salts on electrospinning of aqueous and nonaqueous polymer solutions. Journal of Nanomaterials, 2015, 134251 (2015).

https://doi.org/10.1155/2015/134251 
[26] Verdolotti L., Colini S., Porta G., Iannace S.: Effects of the addition of $\mathrm{LiCl}, \mathrm{LiClO}_{4}$, and $\mathrm{LiCF}_{3} \mathrm{SO}_{3}$ salts on the chemical structure, density, electrical, and mechanical properties of rigid polyurethane foam composite. Polymer Engineering and Science, 51, 1137-1144 (2011). https://doi.org/10.1002/pen.21846

[27] Zhang M., Lai W., Su L., Lin Y., Wu G.: A synthetic strategy toward isosorbide polycarbonate with a high molecular weight: The effect of intermolecular hydrogen bonding between isosorbide and metal chlorides. Polymer Chemistry, 10, 3380-3389 (2019). https://doi.org/10.1039/C9PY00331B

[28] Pankratoc V. A., Frenkel T. M., Fainleib A. M.: 2-oxazolidinones. Russian Chemical Reviews, 52, 10181052 (1983).

https://doi.org/10.1070/rc1983v052n06abeh002864
[29] Li J., Jiang S., Ding L., Wang L.: Reaction kinetics and properties of MDI base poly (urethane-isocyanurate) network polymers. Designed Monomers and Polymers, 24, 265-273 (2021). https://doi.org/10.1080/15685551.2021.1971858

[30] Kamal M. R., Sourour S.: Kinetics and thermal characterization of thermoset cure. Polymer Engineering and Science, 13, 59-64 (1973). https://doi.org/10.1002/pen.760130110

[31] Chern C-S., Poehlein G. W.: A kinetic model for curing reactions of epoxides with amines. Polymer Engineering and Science, 27, 788-795 (1987). https://doi.org/10.1002/pen.760271104

[32] Castro J. M., Macosko C. W., Perry S. J.: Viscosity changes during urethane polymerization with phase separation. Polymer Communications, 25, 82-87 (1984). 